\title{
Investigating preferences in art collecting: the case of the François Pinault Collection
}

\author{
Federica Codignola $^{1}$ D $\cdot$ Paolo Mariani ${ }^{1}$
}

Received: 30 January 2021 / Accepted: 7 September 2021 / Published online: 23 September 2021

(C) The Author(s) 2021

\begin{abstract}
This article focuses on private art collections that play a relevant role on the art market while reducing its information asymmetry. Knowledge of how art consumers such as private art collectors show preferences for specific artworks may allow to identify collecting patterns based on the preference of some artworks' signs. Understanding these patterns is essential for evaluating the impact of art collectors on the art market. The evolution of the art market shows complex consumption systems that shape the cognition and behavior of actors such as private art collectors. Consequently, to be a key art collector and to progress as such in today's art world implies a constant reinterpretation about what it means to consume and to collect art. This paper explores the collection of one of the most important art collectors in the world, the French tycoon François Pinault. More precisely, his background as a key collector was examined, and a number of preferences toward particular signs which connote his collected artworks were identified. All the collected artworks were observed through a descriptive data analysis of the Pinault Collection's exhibition catalogues, published from 2006 to 2015, enforced by the statistical decision tree classifier. Results show how the Pinault Collection is shaped by collecting preferences that can be described as collecting patterns. As a preeminent collector and owner of one of the two major auction houses in the world, Pinault's consumption preferences and decisions may impact the art market, for instance through signals and by influencing other art market players or the artists' careers.
\end{abstract}

Keywords Art market $\cdot$ Art consumption $\cdot$ Collecting $\cdot$ Signs $\cdot$ Signals $\cdot$ Decision tree

Federica Codignola

federica.codignola@unimib.it

1 Department of Economics, Management and Statistics, Università degli Studi di Milano Bicocca, Piazza dell'Ateneo Nuovo 1, 20126 Milan, Italy 


\section{Introduction}

Compared to other product categories, the consumption of cultural and art products is especially linked to subjective features such as emotions or feelings (Hand, 2018; Holbrook, 1980). In other words, it is possible to assess that the artistic product's value primarily depends on subjective feelings induced in the consumer. Only secondarily, it may be related to its functional meaning. According to literature, cultural products are consumed as a consequence of particular behavioral patterns deriving from preferences (Holbrook, 1980; Mellander et al., 2018). In this paper, it is assumed that the consumption of art is equally based on the one hand on a set of functional and extrinsic product's features, and on the other on a series of intangible and intrinsic features (e.g., aesthetic, symbolic, hedonic, etc.). While the former set only deals with objective characteristics, the latter set of features is inherently connected to the consumer's subjectivity. Taking into account the 'art as an industry' debate, some researchers have merely seen the artwork as an industrial product, while others have used semiotics to interpret artworks as products that own an aesthetic sign, which is defined by culture (Barrère \& Santagata, 1999).

The framework of consumption might be of some help in identifying and valuing some behavioral topics related to arts consumption. According to Belk, collecting is a form of consumption (Belk, 1995) therefore art collecting is a form of art consumption. In order to deepen the observation of the topic of art consumption this paper focuses then on art collectors. It appears, also, that collecting is a consumption activity that is more often perpetuated by individuals rather than groups (e.g. families). As a consequence, a case study concerning the collection of one of the most important today's art collectors seemed to be of particular interest. Moreover, as collecting deals with competition with others and exhibitionistic grandeur (Belk, 1995; Jackson, 1976; Muensterberger, 1994) the public figure of François Pinault appeared notably appropriate. In fact, Pinault is a French luxury magnate who competes with few others (e.g. the direct competitor is the French billionaire Bernard Aranult who, just like Pinault, deals with luxury and owns one of the most important private art collections in the world). Finally, it is evident how a person like Pinault inevitably plays a key role in the art market and in the art world essentially by transmitting signals and influencing the market through many levels (artists' economic and symbolic values, artists' careers, auctions' results, other preeminent art collectors' consumption preferences and choices, etc.). This is the reason behind this paper which aims to observe this important collection and to identify and examine any potential consuming and collecting pattern based on some artwork signs' preference.

As for theoretical implications, despite the recent surge in academic articles on private art collections, there is a lack of research on the collectors' preferences that shape their collections. This article aims to fill this gap by studying such preferences, and in particular the signals that preeminent private art collectors send on the market through the collected artists and artworks. In doing this, this article contributes to the literature on art markets and on the more recent topic of private art collections with the development of a new multifaceted theoretical approach. This approach, while observing the implications of consumption in art collection, also 
applies signaling theory to the study of art goods in art collections in order to better understand how these collections reduce information asymmetry regarding their role on symbolic, economic, and market value.

Moreover, the advancement in the exploration of the Pinault case implies an unusual combination of humanities and social science qualitative and quantitative techniques. This choice is due to the fact that the topic of collecting in itself has been so far multifaceted in literature.

This essay is structured as follows. Following the Introduction section, Sect. 2 looks into the literature concerning information asymmetry, signs, signals, and art consumption. This will help better to define a consumption theoretical background, specifically related to fine arts. Such composite speculative framework will contribute to the observation of a key art market subject such as the one of art collectors in order to understand if they respond to some consuming preferences. Section 3 highlights how this study approaches such novel issue by analyzing the case of a private art collection and attempts to discover if the collected artworks and the collected artists are bought and collected randomly, or if they are bought and collected following specific patterns. Practical evidence of the above is provided in Sect. 4 by an indepth examination of one of the most significant private art collections, the François Pinault's collection, through a database that includes all the 885 artworks exhibited by the François Pinault Foundation in four different countries such as Italy, France, South Korea and Russia, from 2006 until 2015. This time frame covers almost ten years of the collection's history as it goes from the first exhibition, "Where Are We Going? A Selection of Works from the François Pinault Collection", in Palazzo Grassi, Venice, in 2006, to the exhibition "Prima Materia", Punta della Dogana, Venice, ended in 2015. Section 5 strengthens the data descriptive analysis of the Pinault Collection's exhibition catalogues through the statistical decision tree classifier analysis which shows how the Pinault Collection is shaped by patterns that can be described as collecting preferences and consequently, as art consumer behaviors. Finally, while Sect. 6, after some concluding remarks, draws attention to some possible managerial implications, Sect. 7 points to the limitations of the research conducted and suggests some avenues for further investigations.

\section{Literature review}

\subsection{Characterization of art goods}

Every artwork encompasses artistic-cultural and economic features. Whereas the economic features relate to the artwork's price (Baumol, 1986), the artistic-cultural features relate to quality. However, both price and quality in relation to art goods are hard to define (Caves, 2000), as in the art market the level of information varies and is never homogeneous (Candela \& Scorcu, 2004; Coffmann, 1991; Ginsburgh \& Throsby, 2006; Rasmunsen, 2006; Shönfeld \& Reinstaller, 2007; Tirole, 1998). The theories on information asymmetry (Akerlof, 1970; Connelly et al., 2011) seem to be particularly appropriate. 
Candela et al., (2012) observe that "When the condition of symmetric dis/information holds, the agents agree on the evaluation of the artwork. However, in the art market neither symmetric information nor symmetric disinformation happen frequently" (290), as the condition of asymmetric information is more common (Candela et al., 2009; Candela et al., 2012; Shönfeld \& Reinstaller, 2007). For the sake of this study, the research of Candela et al., (2012) has proved to be highly significant. In order to examine the issue of artworks' quality evaluation under the conditions of information asymmetry, the authors create a model based on signs and signals intrinsic to the work. Both drive the art market by influencing its demand and supply (Candela et al., 2012).

The above mentioned authors distinguish between signs that are clearly manifested, as "observable" and "unalterable" intrinsic features of the artworks, and signals that, following the signaling theory, are "interpretable" features that parties trade on the market (Connelly et al., 2011). Although signs refer to semiotics and, as concerns to visual art, are based on the visuality of Pierce's semiotics (Leja, 2000), the authors simplify their conceptual implications by indicating that they relate to artworks features such as materials, technique, style, etc. Signals, conversely, are marketer-controlled and easy-to-acquire information that consumers can use in order to infer the product quality and value (Bloom \& Reve, 1990). Scholars have interpreted signals as institutions able to act against the effects of quality uncertainty. They have also identified sets of these institutions, going from guarantees, brand names, licensing practices (Akerlof, 1970), to certification and quality labels (Jahn et al., 2005), and to environmental alliances (Jolink \& Niesten, 2020). In the art field the signals that play a crucial role in reducing information asymmetries are typically associated to the individual artwork and consist on its certificate of authenticity, attribution, provenance, condition, loss history (e.g. Art Loss Register), and literature. Signals, in the art field, refer then also to exhibitions and catalogues.

If we look at the art market's demand and competitors perspective, some of the observable signs and signals inevitably become criteria of guidance or preference and choice when, for instance, a collector prefers specific artworks with determined characteristics, purchases them and inserts them into his/her collection. As for the classification of product attributes based on the level of information asymmetry existing between the supplier and the customers, where Potemkin assigns them the maximum level of asymmetry (Jahn et al., 2005), the above mentioned artworks' signs and signals may impact differently. For instance, while signs are characterized by qualities which can be appraised before and after each purchase (search and experience attributes), signals (e.g. certifications or catalogues) are characterized by qualities that rely on third-party judgments (credence attributes) or by process-oriented qualities unknown to both third parties and customers (Potemkin attribute). In the art world, in fact, no certification is absolutely certain.

Due to the art object's nature, its value dimension based on functional and utilitarian features is linked to its symbolic, aesthetic, and hedonic dimensions. As a consequence, research on art economics touches a multitude of different aspects. Nevertheless, if we explore the aspect of art consumption, we find that only few studies focus on art consumption preferences and choices (Bourgeon-Renault, 2000; Bradshaw, 2010; Grappi \& Montanari, 2009; Slack et al., 2008). Botti's perspective 
(2000) appears here of special interest. Botti observed the concept of the value of consumption through the process of artistic consumption and the enhancement of artistic value among the diverse involved actors. According to this author, the transmission of value among the actors involved in the symbolic and economic process of art is the result of a blending between product centered and consumer centered patterns.

The literature on art markets confirms that the concept of 'art product' is still being debated as, by its nature, an art object pertains to both the materialistic and the creative world (Hirschman, 1983; Kubacki \& Croft, 2011; Lehman \& Wickham, 2014). The 'product' itself results from a blending of tangible and intangible assets (Levitt, 1980). Indeed, on the one hand, it is defined by a set of tangible features such as color, shape, material, size, etc.; on the other hand, it represents and transmits a set of symbolic features such as taste, social status, etc. Together, these two different categories of features enclose all the benefits the consumer obtains when he or she purchases the product.

When we translate such an argument into the arts world's language, any definition of 'art product' verges on complexity. Approaches from all different disciplines concerning this topic show abstract or blurring theoretical boundaries. For instance, Fillis (2006), among others, explained that the difference between consumer products and arts products lies in the fact that this last group has poor or no utilitarian nor functional value. Still, when you think about art with its systems and markets (e.g., museums, galleries, collectors, etc.), often, in addition to symbolic motivations, there are functional and/or utilitarian stimuli. Nevertheless Hirschman (1983) assessed that, differently from the conventional market model, an art product is created in principle as a consequence of the artist's (the producer) own self-aspiration. Only then, such a product is inserted into the art market whose actors and consumers decide whether to accept (and/or buy) it or not. Hirschman has been one of the first authors who have categorized the various audiences and has analyzed the impact of specific networks in the art production process. Thanks to similar perspectives (Boorsma, 2006; Botti, 2000; Hirschman, 1983), it is possible to identify one of the primary roles of key art market's actors such as dealers or private collectors, i.e. the capability to transform a creative and artistic good into an art product. Hence, an art product possesses both intrinsic and extrinsic assets.

If we take into account the art context, it may be interesting to consider the distinction between symbolic products and substantive products developed by Khalil (2000). If symbolic products convey a self-regarding value, the substantive ones convey a functional monetary value. The author assessed that symbolic products may perform, among various possibilities, as vanity goods or as prestige goods, both able to generate self-esteem and admiration. In other contexts, they can serve as pride goods in order to enhance a sense of 'respect', or even function as identity goods in order to increase a sense of 'dignity'. When a private art collector purchases artworks with an investment perspective (e.g., following artists' monetary values and ranking), such artworks may certainly be seen as substantive products. Nevertheless, they may also function as symbolic products: in fact, art collectors' motivations are very often connected to intangible features such as vanity, prestige, status, well-being, etc. (Wheatley \& Bickerton, 2017; Belk et al., 2003; Belk et al., 
1991). Solomon (1983) states that products help build and structure social roles that consumers rely on in order to define themselves. Such consumption behavior along with its social objectives is frequently linked to aesthetic-orientated consumption (Venkatesh \& Meamber, 2006). This type of consumption clearly includes fine art consumption.

\subsection{The implications of consumption in the field of art collection}

From a consumption point of view, an artwork can be consumed through two different forms: it can be acquired and then possessed or it can be observed and contemplated in a private or public exhibition space. Nevertheless, the process of consumption which is represented by the appreciation of the artwork, is analogous in both forms. The artworks consumption forms (that of either acquiring or appreciating in an exhibition space) offer "two different circumstances of consumption: one is through a private, permanent, and ownership-linked approach; the other is through a public, temporal, and circumstantial approach" (Chen, 2009).

Even though many forms of consumption may be found in art (a paying visitor of a museum's permanent collection or temporary exhibition is 'consuming' art; museums' buyers and curators who buy artworks are 'consuming' art; etc.), this paper focuses on the particular case of art collectors. In fact, when they acquire artworks and construct their collection, they can rightly be viewed as art consumers.

Although economics, marketing, and social sciences have certainly contributed to addressing the issue of consumption in arts and culture, the specific topic of consumer behavior in arts appears to be rather peripheral. In particular, research that approaches the topic of consumer behavior in art collecting is scant although some studies do exist (e.g. Chen, 2009; Shönfeld \& Reinstaller, 2007). All the same, in order to better understand the implications of consumption in art collecting, a brief understanding of how consumer behavior theory may relate to art can result of some interest.

The classical economic model of consumer behavior envisages a consumer exploiting a product's value, given the limitations of a specific monetary sum. Moreover, a product's value is determined by considering the product itself as a unique entity. In opposition to this view, thanks to Lancaster's new consumption theory, the product is viewed as a sum of diverse features (properties) that affect the consumer's decision (Lancaster, 1971). Therefore, a consumer decides by choosing among the features of diverse available products, depending on monetary disposition, price, and utility. More precisely, the choice of a consumer depends on a product's best aggregation of features in terms of convenience and efficacy. A similar speculation allows us to define art products' consumer behavior. An artwork, in fact, rather than being viewed as a whole entity, must be viewed, understood, consumed, and eventually bought, through the variety of its natural characteristics (e.g., the material or the media, the size, the colors, the context in which it is displayed or showed, etc.). Moreover, artworks' intangible features may also include the artist/producer's gender, age, nationality, economic value, degree of popularity, etc. 
Taking into account the case of art collectors, all these single characteristics and assets of an artwork, are indeed truly valued and may strongly impact on buying and collecting decisions (Belk et al. 1991; Codignola, 2015).

In their study, Firat and Venkatesh (1993) assessed how in postmodern society an individual makes decisions through hedonistic experiences and emotions. They also stated that as consumption is essentially a social function, individuals consume images instead of functional products and that, through such form of consumption, they build their identity. An art collector who buys selected artworks from selected artists, does live aesthetic, emotional, and hedonistic experiences. At the same time, he is building his own particular identity as a collector.

Part of the consumer behavior's theory affirms that consumers estimate products in different ways, depending on various individual factors (Cova, 1996; Cyert \& March, 1983; Holt, 1995). It is clear that especially in arts, where we deal with aesthetics and symbolic goods, taste, which can influence a consumer decision, changes from one individual to the other. As far as the implications of time in decision-making processes are concerned (Becker, 1965; Bergadaà, 1988), it has been proven that the art collectors' taste also varies depending on the different periods of their lives (Belk et al. 1991).

An interesting part of consumer theory allows us better to frame art collectors' consuming practices. This part refers to the studies of Cova (1996) and Hetzel (1996). While Cova observed how in postmodernity the behavior of the consumer is basically 'erratic', Hetzel noted that such behavior is 'hedonic' and 'eclectic'. More precisely, Hetzel assessed that the postmodern consumer prefers to blend styles and products that are able to reproduce his individuality. At the same time, he seeks consumption experiences that he can perceive as 'ludic'. Once again, these descriptions about postmodern consumer behavior appear particularly appropriate when we take into consideration the subject of art collectors. By their very nature, in fact, art collectors consume actively and longitudinally; search for the joy of an artwork's intrinsic symbolic, hedonic, and aesthetic pleasure; pursue certain dictates of taste and fashion; try to acquire marks of personal status, and so on (Belk et al. 1991; Sherry \& Joy, 2003).

By recalling the traditional marketing theories on cultural consumption, the experiential analytical framework observes the symbolic assets of products' features (Bourgeon-Renault, 2000; Holbrook \& Hirschman, 1982). Aside from looking for a 'solution', individuals, through cultural and art products, demand ludic and hedonistic experiences, and "imaginary and sensory stimulation" (Bourgeon-Renault, $2000,11)$. With regard to consumers' search for experiences, the work of BourgeonRenault on consumer behavior in arts and culture marketing (2000) interestingly showed how "the search for experiences is concerned less with the general characteristics of the consumer (such as socio-demographic variables) than with the intrapersonal characteristics of the individual" (Bourgeon-Renault, 2000, 11). Among the characteristics assembled by the author (Bourgeon-Renault, 2000; Holbrook, 1986; Holbrook \& Batra, 1987; Lee \& Crompton, 1992; McAlister \& Pessemier, 1982; Zuckerman, 2014), some typical features of art collectors can be observed: sensation-seeking; variety-seeking; novelty-seeking; emotions; intrinsic or extrinsic motivations of the individual concerning the cultural product; and visual orientation. 


\subsection{The experiential and the semiological perspective}

The study of Bourgeon-Renault (2000) pointed out that the two major contributions of marketing to the observation of consumption in arts and culture derive from two paradigms: the experiential and the semiological. According to the first one, the consequences of consumers' choices are related to the personal enjoyment experienced by the consumer, rather than to the products' tangible and objective functions. As a consequence, the benchmarks used to estimate the "success of consumption" are aesthetic (Bourgeon-Renault 2000 12). Conversely, according to the semiotic model (Baudrillard, 1972), semiotics is able to understand certain patterns of consumption. All products are made of meanings and these diverge from one individual to the other. If this is true in the field of culture (Baudrillard, 1972; Gourdon, 1982), it is even more evident for art. This means that when we look at an artwork, each of us may consume a different product. In fact, beyond the objective and tangible features of the artwork, we can all respond in a different way depending on our personal feelings.

It is clear that art collectors, as any visitor of an art exhibition in a gallery or museum, correspond perfectly to these consumption patterns. However, an even more appropriate theoretical marketing contribution on art collection consumption behavior derives perhaps from the works of the economic sociologists, Veblen (1899) and Bourdieu (1979). In fact, as will emerge in the next paragraph, one of the most critical dimensions in being an art collector is represented by the social dimension. Both authors examined the divergences between personal approaches and cultural assets over time, in relation to the individual's affiliation to a particular social cluster. Following such reasoning, it is easier to understand and interpret art collectors' consuming patterns. Because an art product exists as a symbol and emanates signs, through the selection of certain artworks or artists an art collector can build a social code and show if he or she belongs to a specific social group or not, or to which social group he or she belongs.

To buy artists that are included in certain quotation price ranges or that appear (or do not appear) in some official rankings of 'success', or, to buy artworks that follow (or do not follow) specific art fashion trends (e.g., figurative art, performances, African art, young emergent art, etc.), may allow the collector to create his own identity and to distinguish himself from the other collectors.

Baudrillard (1972) argued that art consumption is evidenced through sign-goods and depends on social status. Moreover, taking into account the relationship with art products, the process of art consumption is achieved through three stages: possession, organization, and social practice. These phases represent the primary 'moments' of the majority of a collector's being (Belk et al. 1991).

\subsection{Art collection as art consumption}

Collecting is intrinsically 'acquisitive' for the reason that its major objective is getting more of something. As observed by Belk et al. (1991), in today's patterns of 
collecting, "the objects collected are acquired through marketplace purchase; used - through maintenance, display, and related curatorial activities" (Belk, Wallendorf, Sherry, and Holbrook 1991, 179). If one examines the most common existing patterns of art collecting, it seems that the artworks collected are acquired through purchase in the art market and are often maintained and displayed (privately or publicly) with the support of one or more curators. Thus, art collecting is a specific variety of art consumption where art products are purchased, used, managed, and displayed. Belk and colleagues (1991) claimed that collecting represents the greatest example of a consumption activity that is also a form of production in the sense that collectors contribute to producing a "unique, valuable, and lasting contribution to the world" (Belk, Wallendorf, Sherry, and Holbrook 1991, 180). This is obvious in the case of art collectors who opt to display to the public their art collections through the medium of private foundations or galleries. Here, a general public made of various kinds of visitors can have privileged access to great art pieces while, for instance, enriching their education and knowledge. Following the definition of 'collecting' made by Belk and colleagues (1991), an art collection can also be viewed as an activity that is "selective, active, and longitudinal acquisition, possession, and disposition of an inter-related set of differentiated objects (...) that contribute to and derive extraordinary meaning from the entity (the collection) that this set is perceived to constitute" (Belk et al. 1991, 180).

The art collector conceives his collection as a single body due to a perceived wholeness in its elements. The foundation of such wholeness is acknowledged by the labeling of the set of these elements as "a collection of..." and is secondarily defined through the borders that the collector stipulates. These observations strengthen this paper's analysis. In fact, this paper aims to investigate, through the observation of one of the most important private art collections in the world, how the single body of such collection has been constructed along the years; by which signs the set is composed; if there are any recognizable boundaries fixed by the collector; etc. This will help understand if François Pinault purchases and collects artworks by preferring determined artworks' signs. In that case, results will generate a François Pinault's consumption and collecting pattern useful for other art market players such as artists, other collectors, etc. If we interpret Pinault as a signaler, the collecting pattern of one of the major private collectors in the world could represent a significant signal able to reduce the art market information asymmetry.

\section{Research framework}

The art market is a complex system articulated over different levels-global, national, and local—structured around a heterogeneous and complex institutional system built around various players. These players represent a circuit of production, diffusion, and commercialization of the artistic items. Therefore, the art market might be seen as a cluster in which heterogeneous (by nature and by influencing relevance) subjects interact, all driven by the purpose of satisfying the aesthetical and cultural needs displayed by the art beneficiary or the art consumer. Together with 
this classic purpose, art consumers may also be driven by speculative and investment objectives (Mei \& Moses, 2005).

Through the years, the art market has suffered a radical reshaping and has been revolutionized from its core (Velthuis, 2012). Evidence of these changes is to be found in longitudinal observations concerning the subjects and the institutions that play a role in the field. The end of the government patronage era in the late nineteenth century led to the advent of a market for artworks that slowly grew to become the multi-billion business that is today. This transition led to an impressive change in the art market actors' concept of such a market or the creation of new institutions (e.g., publicly accessible private art collections).

The flow of time and the evolution of the artistic scenario have always shaped the art market. The foremost peculiarity of the field is its perpetual transformation and its constant evolution in a never-ending stream of new forms. Thus, today's art market is shaped by heterogeneous segments of subjects and products (e.g., among the art products distribution system or among the production field itself). It may depend on the degree of appreciation of the consumers and on their personal preferences.

The heterogeneity of the field is also determined by many other criteria, based, for instance, in spatiality (global market, national market, local market); temporality (ancient art, modern art, contemporary art, etc.); genre (painting, sculpture, photography, performance, video, etc.); distribution (primary, secondary market, etc.); and consumption power (the level of the purchasing power of buyers). The mechanisms through which such criteria function and revolve around the economic rationale and the artistic rationale may be extremely complex. In fact, today, they mostly depend on the interaction of players that constantly reinterpret what it means to produce and consume art (Frey, 2000).

\subsection{Today's categories of art collectors}

Art collectors have always been central in the demand for artworks. Usually, the uniqueness of the product and its possession are behind their consumer motivations. Unlike collectors of other cultural products, for whom the possession of a reproduction does not weaken its intrinsic value, art collectors are affected by the connection between the aesthetical message and the original material support of the artwork, which is directly and uniquely created by the artist.

What from now on we describe as large-sized art collectors (LAC) consists of a special category of collectors who often show all their numerous acquired artworks in a private museum or a section therein. In the LAC case, the role of the collector is double. On the one side, the direct aesthetical fruition of the artwork for the broad public (described as the public's cultural consumption act) is guaranteed; on the other side, the personal need to privately possess the artwork is satisfied. In other words, LACs are simultaneously guided by the artistic and aesthetic ratio, by values linked to fruition, and by the economic ratio and values linked to possession. As for the standard art collector's profile, there is consensus on the fact that LACs, besides the aesthetical ratio, are also shaped by specific psychological, social, and economic values (Molfino et al., 1997). For instance, the need to collect artworks, increased 
in line with the improvement of the western's standard of living, is the result of a desire for self-assertion through a process of materialization of artistic values. For that reason, aesthetic values are of crucial importance because cultural knowledge and aesthetic sensitivity are both fundamental conditions in the building of highquality art collections. Not only they allow distinguishing authentic artistic values from trendy ephemeral values, but they also allow for profitable investments in a perspective that is both economic-driven and prestige-driven (Cesarano, 1967).

Zorloni and Willette (2014), however, suggested that the artworks' demand is conditioned by limiting factors, such as an expendable income. Therefore, the willingness to buy artworks increases with the increase of income provided that, simultaneously, art knowledge and art culture also increase (Zorloni \& Willette, 2014). In fact, an individual benefits in the highest degree from an artwork purchase when both the personal cultural level and the social-cultural participation in shows, vernissages, biennials, fairs, etc. are high. Thus, in light of these considerations and taking into account a basic criterion such as the dimensional one (founded on the collection's density), it is possible to distinguish LAC from the category represented by the small and medium-sized art collectors (SMAC). This category consists of the medium and high sections of the middle class and by individuals who desire, for passion's sake, to enter the process of artworks accumulation by investing moderate amounts. SMACs are indeed an active part of the art market demand, but from a strategic perspective, they do not have any particular influence. Their importance is directly linked to the total turnover they contribute to as buyers. Individually, they do not have any relevant role.

Instead, LACs help to evaluate art collecting also as a business. Publicly available data (e.g., interviews; newspaper and magazine articles; other media contents) all view their involvement through financial lenses. In fact, LACs' semantics revolve almost exclusively around the collectors' financial features and avoid other perspectives, such as personality, aesthetic or artistic-driven ideas and attitudes, and cultural knowledge.

As a consequence, media under-represent LACs' fundamental cultural role. LACs do sustain the living artists they choose for their collection and make their economic and artistic affirmation possible. When they open a private museum, LACs also contribute to develop and enhance the opportunity for the public to benefit from an important cultural and artistic flow that in turn may create new cultural knowledge.

Besides the diverse amounts of their investments, another way to distinguish between today's art collectors is to take into account their consumer behavior in terms of purchasing choices. One can easily categorize traditional and conservative art collectors (TAC) as well as avant-garde and innovative art collectors (AIC). Still, intermediate situations exist that are characterized by diversified interests and needs. This is the reason why art collections constantly evolve and are renovated, just like artistic movements. All in all, if TACs generally show less risky attitudes and buy artists with stable quotations or with a solid and recognized name, AICs are more sensitive to novelty. Thus, they are more inclined to risk by choosing artists who are young, emergent, or even unknown. ARTNews 200 Top Art Collector figures (ARTnews, 2018) showed that AICs' interest in art can be interpreted as an expression of a dynamic lifestyle (in terms of professional career, income, travels, 
social life, etc.) characterized by cultural ambitions. Moreover, AICs mostly belong to the category of extremely wealthy individuals who at some point decide to create their personal collection. Their motivations range from the love of art to the enhancement of their social image, to a financial one, etc. In any event, AICs play concrete roles and produce tangible consequences in the art market (Polveroni \& Agliottone, 2012, 89).

Therefore, today's art collections are indeed a product of their times. Not only do they give testimony to the contemporary artworks and in doing so represent the taste and the culture of their era, but when they interrupt conventional and recognized patterns, they also reveal the innovative power of change. That is why every era reinterprets what it means to consume art through new models and diverse conceptualizations of collecting.

\subsection{The François Pinault Collection}

Pinault is a French luxury goods magnate who is honorary chairman of the luxury group Kering Pinault's. His huge business involvement and his passion for art, sustained by a strong financial capability-according to Forbes, his worth amounted to $\$ 28.4$ billion in 2019 - have made the realization of one of the most important art collections (from the twentieth and twenty-first centuries) of the world. He owns a 3000-piece art collection which he variously houses and exhibits all around the world. The Pinault Collection's museums are housed in two buildings in Venice: Palazzo Grassi, inaugurated in 2006, and Punta della Dogana, opened in 2009. Artworks in the Pinault Collection are displayed in exhibitions that often involve the artists directly through specific commissions to create new works in situ. The Teatrino, inaugurated in 2013, is organized in collaboration with institutions and universities in Venice and abroad. In 2020, the new museum of the Pinault Collection will open in Paris, inside the Bourse de Commerce. Artworks in the Pinault Collection are also recurrently presented in exhibitions across the world. Solicited by public and private institutions, the Pinault Collection loans many of its works to international exhibitions (Palazzo Grassi, n.d.).

The importance of the collection also resides in the dramatic number of contemporary artists collected - most of them living, emerged, and emerging artists - and in the artistic and economic potential of their artworks. Pinault's several interviews always humbly point out how he nourishes the passion for art by learning from the art world and by actively participating in it (Elkann, 2012; Gnyp, 2015). He explains that in the selection of his artworks, he has always considered extremely important to build a relationship with the artist. Thus, his role as a collector does not consist only in the detached purchase of an artwork, but it involves an authentic relationship with its creator - a most important element when considering his ability to positively influence an artist's career.

In sum, taking into account public available data and interviews, it is possible to identify Pinault has a preeminent art market player (LAC); besides, it emerges how in his approach to his profession and collection the symbolic (e.g., aesthetic) and the functional (e.g., market rationales) are both evident and constantly alternate. The 
analysis of the database along with the recognition of some collecting patterns will instead help us to identify whether Pinault belongs to the TAC or the AIC collector categories.

\section{Data collection and procedures}

The examination of the Pinault Collection provides practical evidence that allows us to observe for the first time the process behind an art collection as a consumption process within specific preferences that can be interpreted as collecting patterns.

Until now, this paper has first contextualized the process of art collection through the theoretical framework of consumption; secondly, it has defined its research context by focusing on today's art market and today's collector categories. Finally, the collector's background in terms of values has been taken into account in order to examine his role - with regard to the collected artists and other players of the art market - and to examine his general attitude as a relevant collector.

The specific collecting features and motivations of Pinault are observed through an objective validation. More precisely, by interpreting exhibitions alongside with their catalogues as signals, a significant part of the publicly displayed collection is analyzed in order to identify some collecting patterns of Pinault.

To do so, Pinault Collection's data were collected, and a database was constructed to include all the 885 artworks realized by 212 artists and shown through fifteen exhibitions held around the world from 2006 to 2015 (Palazzo Grassi and Punta della Dogana, Venice, Italy; Conciergerie, Paris, France; Song Eun Foundation, Seul, South Korea; Dinard, Bretagne, France; Garage Melnikov, Moscow, Russia; Tri Postal, Lille, France). Artworks' data were extracted from the exhibitions' catalogues, both online and printed (www.Palazzograssi.it).

This database lists the title of the artwork, some information about the artist (e.g., name, date and country of birth, country of work), and the name and time of the exhibition. The fifteen exhibitions examined are the following: A Triple Tour; Prima Materia; Voice of Images; A Selection from the François Pinault Collection; The World Belongs to You; In Praise of Doubt; Agony and Ecstasy; Qui a peur des artistes?; Mapping the Studio: Artists from the François Pinault Collection; Un certain état du Monde; Passage du Temps; Sequence I: Painting and Sculpture from the François Pinault Collection; François Pinault Collection: a Post-Pop Selection; Picasso, la joie de vivre; Where Are We Going? A Selection from the François Pinault Collection.

A variable 'Entry capability' was created to represent the speed through which each artist accessed the Pinault collection. After calculating how many years the artist has been in the collection, this value was compared to the global presence in the rank. The average of this index was used as a benchmark. The entry capability is 'Fast' if the value is greater than the average, 'Slow' otherwise. At the end of this pre-processing 123 artists are present into the database.

The data analysis was carried out through the descriptive analysis and using the decision tree classifier. This approach was used to divide a dataset into successively smaller sets by applying a sequence of decision rules. Each successive division 
contained a homogeneous group with respect to a particular target variable that is usually categorical (Kass, 1980). For each record, the root node applies a test to determine which 'child' node the record will encounter next. This process was repeated until the record arrived at a 'leaf' node. The path is an expression of the rule used to classify the records. Classification trees usually apply to output variables that are categorical in nature. They can be easily represented in a visual way, and the corresponding decision rules are quite straightforward. Additionally, because the result is a series of logical if-then statements, there is no underlying assumption of a linear (or nonlinear) relationship between the input variables and the response variable (EMC Education Services, 2015). For growing algorithms, we used CHAID — Chi-squared Automatic Interaction Detection (IBM, 2012). A decision tree is a natural choice when the goal is to generate understandable and explainable rules (Berry \& Linoff, 2004).

Two statistical objectives were identified. The first objective was to assess the presence and nature of Pinault's own collecting patterns that, for instance, could allow us to understand if he belongs to the TAC or AIC collector categories. The second objective was to identify a comparative speed of access, if any, to the Pinault's collection on the part of individual artists, based on selected variables (the artworks' signs).

In order to define if the Pinault case shows specific collecting patterns, our hypothesis was that, as for his purchases, Pinault prefers to acquire artworks from: (a) French, (b) male, and (c) emerging or young emerged artists. This hypothesis was based on the following arguments:

(a) firstly, in opposition to some art markets' literature that affirms that the current market can be seen as a global one with very blurred boundaries between countries (Codignola, 2015; Velthuis \& Baia Curioni, 2015), there is still a strong connection between the country of origin of the artist and the country of origin of the art purchaser. Therefore, a collector may tend to buy artworks from artists that possess his same nationality;

(b) secondly, some studies have shown that in contemporary art, in addition to Western hegemony, male hegemony is also prevalent among artists (Merlin, 2019; Reilly \& Nochlin, 2007);

(c) thirdly, by following the major art market's trends, the high-end collector segment (LAC) is characterized by riskier attitudes and prefers to purchase emergent or young emerged artists. In doing so, such segment would also follow the behavior of the avant-garde and innovative art collectors (AIC) segment.

The next section empirically evaluates and demonstrates the above hypothesis.

\section{Pinault's collecting preferences}

As shown in the theoretical background section, studies on art consumption constitute a fundamental economic approach that allows us to examine in detail the nature of art collector as art consumers. Consumers act through personal and varied motivations and preferences that firms usually take into account in order to shape 
efficient business strategies. Many features influence consumer preferences and choices in art. Such features can have social or cultural origins, or can be linked to personal motivations, convictions, or attitudes. Normally, it is difficult to go deep into these aspects and to understand them. Some consumers' incentives certainly derive from the market environment (e.g., distribution, promotion), while others derive from the external environment (e.g., social, cultural, economic features, technologies, etc.). Consumers' answers are translated into consumer behavior, preferences, and attitudes (Kotler \& Armstrong, 2010, 154-155). For their part, art collectors are influenced by features inherent in the nature of the art market and by other features deriving from the external environment.

In the case in point, this paper sheds light on art collectors' consumption patterns and traces a profile of a specific and preeminent art collector by examining a dataset based on the majority of his possessed artworks. We used data collected from Artfacts (2015-2019) and we selected some variables that, from a qualitative perspective, could help structure a Pinault's consumer profile shaped on his patterns of artworks' selection. This exercise is made possible through the frequencies distribution analysis of several artworks' signs which are the artist's gender, age, country of birth and country of work. We can conduct our analysis by considering a population-the artists of the Pinault Collection-and a number of variables that must be evaluated through their trends and possible connections.

We applied a frequencies distribution analysis to the names of the 123 artists of the Pinault Collection to represent the different modalities of a feature distributed among statistical units that form the overall issue of this study (Table 1). When applied to Pinault's collecting patterns, data showed a solid preference for purchasing more artworks produced by male artists $(82.1 \%)$ than by female artists $(17.9 \%)$.

We used an explorative approach to verify whether Pinault's collecting patterns are more oriented towards young artists or senior/deceased artists (class 70+) with a recognized name, a solid rank, and a confirmed reputation. Data showed that Pinault predominantly prefers young and working artists. A critical side effect of this preference is that the artists' future careers can be influenced by their inclusion in the Pinault Collection.

We realized that 40/49-year-old artists represent the main segment of the Pinault Collection. This confirms that Pinault prefers artworks made by artists at the height of their creative and artistic production-but not, for instance, in a later stage. In fact, results partly confirmed our hypothesis and showed that he prefers to buy artworks from the two contemporary art market's segments of emerging and young emerged artists. Consequently, as such segments represent the highest trends in the contemporary art market, it can also be argued that Pinault's own collecting patterns may appear investment-driven. Moreover, this pattern suggests that Pinault belongs to the AIC collectors' category. Young artists are potentially more promising actors in the contemporary art market, for both their productivity and their financial potential. Concomitantly, the presence of these new talents in the famous Pinault Collection constitutes a jumping point for furthering their career.

This first step in the analysis of the Pinault Collection, along with features such as the artists' age and gender, considered two more signs: the artists' geography (where they were born and where they work), and the artworks' genre. 
Table 1 Distributions of Artist by gender, age in class, continent, artwoks' genre, year of access in Pinault collection, entry capability (2006-2015)

\begin{tabular}{|c|c|c|}
\hline & $\mathrm{N}$ & $\%$ \\
\hline \multicolumn{3}{|l|}{ Gender } \\
\hline Female & 22 & 17.9 \\
\hline Male & 101 & 82.1 \\
\hline \multicolumn{3}{|l|}{ Age } \\
\hline $30-39$ & 8 & 6.5 \\
\hline $40-49$ & 38 & 30.9 \\
\hline $50-59$ & 20 & 16.3 \\
\hline $60-69$ & 17 & 13.8 \\
\hline $70+$ & 40 & 32.5 \\
\hline \multicolumn{3}{|l|}{ Continent } \\
\hline Europe & 54 & 43.9 \\
\hline Asia & 20 & 16.3 \\
\hline Africa & 8 & 6.5 \\
\hline Oceania & 1 & 0.8 \\
\hline North America & 35 & 28.5 \\
\hline Central America & 4 & 3.3 \\
\hline South America & 1 & 0.8 \\
\hline \multicolumn{3}{|l|}{ Artworks' genre } \\
\hline Installation & 11 & 8.9 \\
\hline Sculpture & 6 & 4.9 \\
\hline Painting & 20 & 16.3 \\
\hline Multimedia & 74 & 60.2 \\
\hline Photography & 7 & 5.7 \\
\hline Other & 5 & 4.1 \\
\hline \multicolumn{3}{|c|}{ Year of access in Pinault collection } \\
\hline 2006 & 26 & 21.1 \\
\hline 2007 & 21 & 17.1 \\
\hline 2009 & 33 & 26.8 \\
\hline 2011 & 17 & 13.8 \\
\hline 2012 & 13 & 10.6 \\
\hline 2013 & 13 & 10.6 \\
\hline \multicolumn{3}{|l|}{ Entry capability } \\
\hline Slow & 61 & 49.6 \\
\hline Fast & 62 & 50.4 \\
\hline Total & 123 & 100.0 \\
\hline
\end{tabular}

Source: Calculations on Pinault Collection's data

By looking at the geography of Pinault's collected artists, one might be led to believe that nationalism or nationalistic empathy impact on his collecting patterns (Codignola, 2015). This, in effect, was part of our working hypothesis. On the contrary, data supported a different argument. It seems that Pinault possesses a profound knowledge of the contemporary art market - intrinsically influenced by 
globalization and its evolutionary nature - and a sharp critical behavior that, coupled by his uncommon intellectual honesty, allow him to recognize profitable market trends irrespective of any nationalistic bias. Besides being an art aficionado, Pinault is also a businessman. Therefore, in his collecting patterns the artistic ratio is inextricably entwined with the economic ratio. Thus, we argue that the investment logic has a notable impact on the selection and purchase of contemporary artworks for his collection. Today the United States and China represent the two key actors in the growing economic contemporary art market on account of a favorable taxation system that encourages import and export, and of the increasing value of emergent American and Asian artists. Still, the Pinault Collection evidences a significant selection of European artists, presenting other motivations at play on top of economic ones.

In this segment of Pinault Collection's artists are mainly European (43.9\%); specifically, they were mostly born in Italy, France, and the United Kingdom. Coming just after European artists, North American artists represent a 28.5\% of the overall number, followed by Asian artists (mainly from China) with $16.3 \%$ (but market trends and data indicate a quick projected growth in China's share). In sum, the results disconfirmed our hypothesis that Pinault preferred to purchase artworks from artists of his same nationality.

Results were quite different when the country of work was examined. Such heterogeneity may depend from different factors, one of which certainly is the variety of European art tax rates. These inevitably affect markets' competition and dynamics. Any art collector who invests must be aware of the fiscal and normative regulations of the country in which he intends to make a transaction, and of local incidental and overhead expenditures. When Pinault purchased Palazzo Grassi as the lieu of his exhibitions, he had to evaluate the implications involved in Italy's fiscal regime. Probably, financial implications are somehow behind his selection of artists active in Europe as opposed to artists active elsewhere. The relative high percentage of North Americans might be related to the fact that, apart from federal taxes, in Canada and in the United States there are no import or export taxes. Conversely, the Asian segment might be influenced by China's 17\% VAT on imported artworks, in addition to a $12 \%-14 \%$ custom fees for paintings and sculptures and $7.5 \%$ for prints. An additional reason lying behind such a prevailing of purchased artworks from artists working in France is purely pragmatic. The fact that Pinault himself is essentially based in Paris, which is one of the Western art capitals that hosts some of the most important art market' events, circuits and actors (Codignola, 2015), enhances the opportunities of acquaintances and connections between the collector and the artists. In this application, most of those who change countries go to the USA, France or Germany. In sum, by taking into account not the artists' nationality but the artists' place of work, part of the paper's hypothesis was instead confirmed.

Yet another way to examine Pinault's collecting patterns is through the artworks' genre. Contemporary artists do not produce artworks exclusively through classic and traditional art forms such as prints, paintings, sculptures, etc. Instead, they create through a multitude of forms and media, such as performances, videos, installations, etc. These forms imply various participatory acts for both the artist and the public. Art market's figures and trends show that artists are more 
and more integrating such different forms by experimenting and creating art shapes that overcome the prefixed classical canons of painting and sculpture. Through these current artistic multiple forms and expressions, often supported by technology, artists may approach their own themes more incisively.

In fact, Table 1 shows that the most common genre in the Pinault Collection is multimedia (60.2\%), the category which includes and assembles various forms of artistic representation. Painting represents $16.3 \%$ and photography 5.7\%. Results reinforce the previous assertion that identifies Pinault as an AIC collector in line with his preference for emerging or young emerged artists as these segments tend to produce more multimedia artworks. Such speculation partially confirms our hypothesis.

We attempted to observe more closely the collecting patterns of Pinault, by looking at them from an opposite perspective, that of his artists. We introduced the 'Entry Capability' variable, which represents the speed through which each artist accesses the Pinault collection. ('Accession' means a first appearance in a Pinault exhibition). This variable was added to our analysis of the data as presented so far. By using the decision trees as a classifier, we linked this 'speed' to the following variables related to the artists: gender, age in classes (the 70+ class includes deceased artists), continent of origin, artwork genre and the year of accession to the collection.

With regard to the Entry Capability variable, the main tree (Fig. 1) shows a percentage of 49.6 for Slow and of 50.4 for Fast. The year of access to the collection the first choice of the model; it shows three partitions: the first includes the years 2009, 2011, and 2012 (Slow), the second partition includes the years 2006 and 2007 (Fast), the third one includes 2013 only (Slow). The first partition differs as regards the age in classes variable. A further partition into four typologies is done. The first, second, and third partitions $(40-49,50-59,60+)$ are described as Slow. The third partition $(60+)$, however, is linked to the artist's gender-faster if painting, slower if multimedia, sculpture, etc. The only Fast one is the 30-39 age class, where Asia appears slower, and Africa, Europe, and North America, are faster.

By and large, the period 2006-2007 presented an acceleration and the year 2013 showed a deceleration. As for the other years, access was related to specific paths. For example, paintings were preferred as regards $60+-$ artists, whereas the continent of origin seems to be crucial as regards young artists. So far, the gender factor is absent. This classification had an error margin of $91.9 \%$ according to the CHAID method.

Some significant behaviors are detectable when speed access was evaluated in conjunction with an artist's individual features (Fig. 2). Although the percentages of classification accuracy are not especially high, the gender variable shows a higher speed for males. Africa, Europe and North America are the fastest continents, followed by Central and South America, while Asia and Oceania are still slow. Young artists (30-39) are faster, followed by 60-69 artists, whereas central and higher ages, together with deceased artists are slow. Multimedia, painting, photography and sculpture are quicker than other genres. The access years 2006 and 2007 are fastest. 


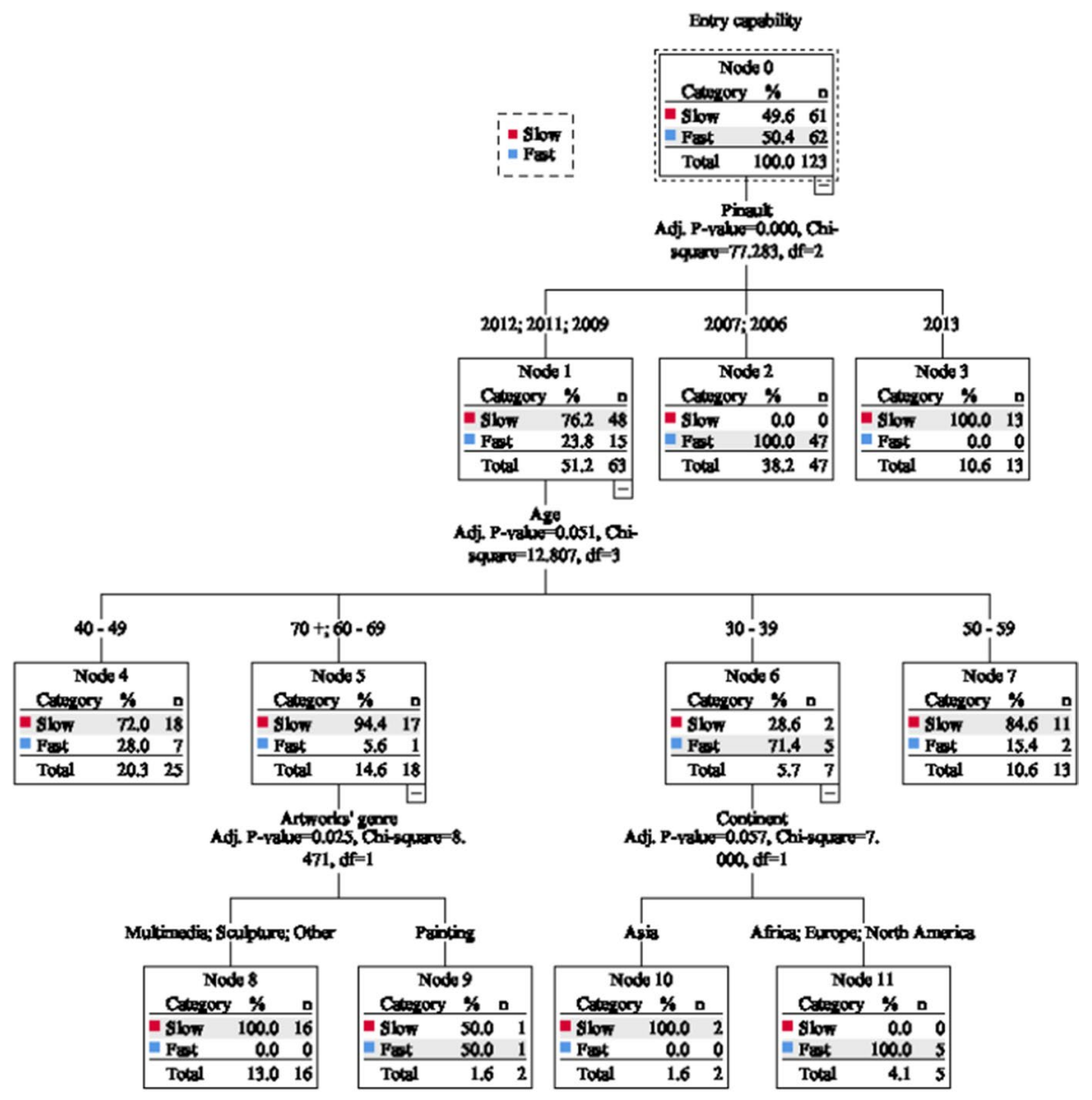

Fig. 1 Decision Tree Entry capability-year of access in Pinault collection, age in class, artwoks' genre, continent (2006-2015). Source: Calculations on Pinault Collection's data.

\section{Theoretical contributions and managerial implications}

This article has studied the case of a preeminent private art collection that may function as an important signal on the art market. Since the study of private art collections and the implications of consumption in this field are a relatively recent topics, there is substantial room for making contributions to this literature.

Our article contributes to the literature on the specific segment of private art collections in several ways. Firstly, the paper's key findings show that the Pinault Collection is shaped by collecting preferences that can be described as collecting patterns and consequently, as art consumption behaviors. In fact, in the frequency's distribution of determined artworks' signs represented by selected variables (e.g., artist's gender, age, birth and chosen country of activity, or artworks' genre), a number of these signs appear to be recurrent. The analysis of the Pinault Collection 

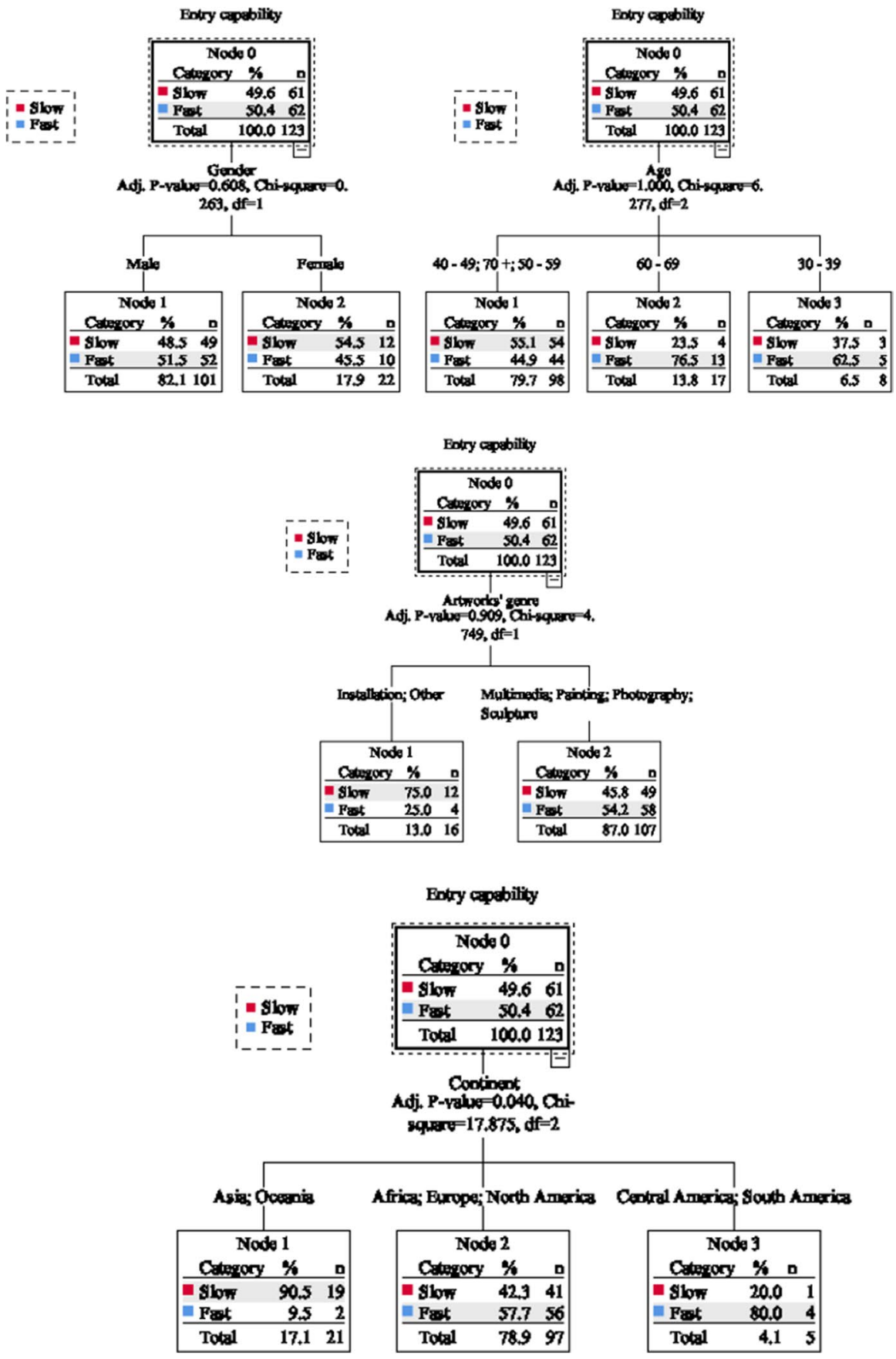

Fig. 2 Decision Trees Entry capability_gender, age in class, artwoks' genre, continent (2006-2015). Source: Calculations on Pinault Collection's data. 
evidences the collector's own collecting patterns, one that is mainly characterized by a distinct preference for: male artists; artists aged forty or fifty (e.g., in the middle of their creative and productive career); artists mostly working in Europe and in North America (in particular in France); and artists that create cross-media artworks (e.g., performances, videos, installations, etc.). These results confirm our hypothesis according to which through the analysis of the Pinault Collection we would have found a predilection for Western emerging or young emerged male artists who, in particular, work in France, as the collector does. Although through publicly available interviews Pinault leaves economic discourse at bay, he selects specific artists who are not randomly chosen. Instead, they mostly belong to explicit art market trends that are formed by high-ranked young emerged artists or "recognized" (e.g., by the critics, by high-end galleries and dealers, etc.) emerging artists, who are mostly Western, or Western-naturalized, based in France, male, and produce crossmedia artworks (also, the most popular trend among the above cited contemporary artists' genres). In sum, he undoubtedly purchases and collects artworks from artists that are fashionable and explicitly valuable in market and investment terms. Of course, the nature of the business he conducts gives him away. Suffice it to say that he owns Christie's, one of the two leader auction houses, where the same artists he displays through his private museums and exhibitions are sold every day realizing impressive monetary performances. In fact, indicators evidenced in this study show that in Pinault's attitude as a collector the symbolic (e.g., hedonic, artistic, aesthetic, etc.) rationale is certainly highly sustained by a functional (e.g., business) one.

Secondly, this article contributes to the research on art markets as findings show how consumption in the art market is never merely driven by profit (Velthuis, 2005). Artworks' prices can in fact also be viewed as social constructions subject to interpretation across quantitative and qualitative lines. Art markets simply convert intangible values into fungible values (in monetary terms). The economic logic is not detrimental in nature and therefore does not need to be condemned, but rather to be understood as a conveyor of meaning. At the same time art collecting is strongly subjective and its understanding is conditional to the study of consumer behavior in arts.

Thirdly, and as for the possible managerial implications of this study, by applying signaling theory, we enlighten how the Pinault Collection, François Pinault, being one of the key players in the segment of LACs and AICs, represents a relevant signal in the art market. Therefore, in this sense, our research may be of some theoretical interest in order to approach the topic of consumption in art especially if we consider how the collecting preferences of a key art collector can influence the art market, for instance by affecting other art market players or an artist's career. To be a key art collector such as Pinault implies that his collection is constructed through an aggregation of systems and actors (e.g. curators, critics, art historians, etc.) that are an implicit certifying system. His collection, then, while reducing the information asymmetry within the art market, represents in itself an institution able to establish a quality reputation, as its artworks and artists are accepted as a quality surrogate (Jahn et al., 2005). Artworks are too complex for consumers and many of their features are too intangible or time-costing for them to evaluate. Art consumers then, can instead rely on easy-to-examine signals such as those of a preeminent 
art collection that generate inferences on which artworks and artists' attributes have superiority and value (Bloom and Reve, 1990).

Operating as they do at the highest levels of the art market, LACs have in fact central roles. They enhance and promote artists; act as opinion leaders and influence other collectors' consumer choices; counsel and influence museums' boards; act as art critics or curators when managing their collections and exhibitions; act as patrons when donating artworks or sustaining artists; contribute to the diffusion of art knowledge and culture when opening private museums to the public; and participate in the economics of the art market when selling their artworks. As the French collector can be seen as a quintessential representative of the LAC and AIC categories, he can considerably affect an artist's success. More precisely, the fact of being present in a collector's exhibition may affect an artist's values and career. The special relationship between artists and collectors - often based on reciprocal trust - positively influences the artist's career in that it allows his work to be associated with 'quality' parameters. The simple fact of belonging to a relevant collection such as the Pinault Collection may then allow the artist to gain higher ranking positions and to increase the number of future exhibitions. Therefore, LACs and AICs role appears to be a key one in the contemporary art market, particularly so in the personal relationship LACs and AICs establish with the artist. LACs and AICs have a strong molding influence on the artist's reputation and profession.

Alongside with having assessed the presence and nature of Pinault's own collecting preferences and consumption attitudes, this paper has also compared the collected artists' speed of access to the Pinault's collection through the 'Entry Capability' variable. This part of the analysis confirms our previous findings: male artists; North American, European, and African artists; and young artists of the 30-39 age class are faster. As far as African artists are concerned, this apparently new element is due to the fact that a good number of them are active either in North America or in Europe. As for the 30-39 cohort, they appear to be a younger section of what we had previously identified as a slightly older "recognized" emerging artists' segment.

According to Jyrama and Ayvari (2010), in the art market actors are either business-oriented (e.g., dealers, consumers, etc.) or institutional (e.g., art schools, critics, museums), with markets hierarchically ordered by status and reputation. A key art collector such as Pinault, with his immense collection, which is publicly accessible, overcomes the above mentioned dichotomy. This fact also further implies that as a hybrid subject in the art market he can actively influence the art market in multiple ways. These collaborative relationships, typical of the art market, signify that the perceptions of the art product's quality, along with the possibility for an artist to be perceived as successful, are collectively created, and directly connected to the single artist's reputation as determined by key subjects in the art world such as Pinault (Chong, 2005; Martin, 2007).

Given the importance of Pinault's role in the art market, a further contribution of this article to the art market literature and to the private art collections literature resides in the fact that this study has chosen to observe in depth his collecting patterns by viewing his art collection through the lens of consumption preferences, therefore by considering Pinault as an art consumer and the artworks he purchased as art products. 
Consumption in the artistic field may be explained by way of the sensory, emotional, and imaginative features of the consumer's personal experience. However, in this paper this approach has been meaningful only for the framing of the figure of Pinault as a collector, through interviews and statements where he has effectively referred to such features. In agreement to consumption theory, relevant social changes which have transformed consumption patterns in art have appeared. In this paper, we have ascertained that such changes correspond to important changes in the art market, where new patterns of collecting have been created. For instance, just as revealed by postmodern literature in consumption, art consumption represents a social experience. We have found in the figure of Pinault a dichotomic coexistence of a logic of distinction (e.g., as a preeminent art collector who possesses one of the major art collections in the world) and a logic of identification with community. The latter is exemplified by Pinault's desire to share his collection and create social interaction (e.g., through the creation of his private museums and spaces where the collection is open to the public or through the loan of his artworks for exhibitions in other museums). However, from a managerial perspective, it is arguable that Pinault, through his collection, transmits signals to the market and to society in order to differentiate his luxury business approach, gaining at the same time, a consistent competitive advantage.

The empirical results of this study have evidenced specific patterns of consumption that can have two sorts of implications that confirm what has been mentioned above. From the one hand, they show how the collector, in his first nine years of public display of his pieces, has revealed a concentration on several specialties within the area of collecting contemporary art. As explained by Belk et al. (1991), the first motivation behind such specialization is to put forward challenges that present a reasonable chance of success (achievement and superiority over other collectors). This may allow us to identify Pinault's role as an art collector, as functional to the enforcement of Pinault's role as a luxury tycoon (e.g., status). From the other hand, the fact of purchasing artworks from artists that generally follow the art market trends shows that the market rationale has undoubtedly affected the symbolic one (made of emotions, etc.). After all, as Pinault is also the owner of Christie's, such evidence is of no surprise as it entails precise business logics. The above arguments further enhance the signaling role of the Pinault Collection in the market. The value of art resides in some cases more in the function of social consensus than in the perceived needs of consumers (Shubik, 2003). The public and business figure of Pinault, together with his collection, has developed a renowned reputation. Such reputation alone represents a strong signal about the collection's capability in selecting high potential art trends and artists while reducing other buyers' risk when acquiring art. It follows that the collection's patterns are a signal easily understandable even without any particular expertise. Moreover, the reputation of the collection and of Pinault are entwined and reinforce each other. To conclude, valuable signals can give organizations and actors a strong competitive frame even in the art market. Since some of the global art market's trends are pointing at the enhancing of the significance of signals in the marketing attempt, art market managers should consider careful long-term planning in their effective signaling strategies. Managers from galleries, fairs, museums, private collections, auction houses, etc. should 
follow this direction while developing, for instance, competitive analysis and consumer research.

\section{Limitations and future research}

The main limitation of this study resides in the fact that only one of the global preeminent private art collections has been taken into account. A comparative analysis of the major collections would gain more representative results in their theoretical and practical implications. A further limitation refers to the limited timeframe examined: the construction of the Pinault collection is ongoing and the data examined in this study should be compared to the ones pertaining to what could be called a 'second period' of the collection. This would allow to detect why its collecting attitudes still follow the patterns emerged from this study. Future research, when examining a preeminent private collection, should also enlarge the selection of artworks' signs used in this study. This would extend the observation's spectrum while allowing a deeper understanding of the topic of art collecting and consumer behavior in art.

The history of art collecting, its actual institutional implications, and the societal roles provided by art collecting doings in today's global economies help understand the unique relevance of art collecting in today's consumer culture. As a consequence, to research the topic of art collecting is not only to observe the singular significance and role of art consumption but it means also to understand the patterns of the actual art collecting condition. However, various issues confronting research in the field of artistic perception of the consumer are still unresolved. In such a perspective, the theoretical framework of asymmetric information, along with the function of signals in the art market context, should be kept in mind. Finally, it is yet to be determined which are the main signals in the art field and in the market, and which of them play the most crucial role.

Funding Open access funding provided by Università degli Studi di Milano - Bicocca within the CRUICARE Agreement. Not applicable.

Availability of data and material Data available upon request.

Code availability Not applicable.

\section{Declarations}

Conflict of interest I have no conflicts of interest to disclose.

Open Access This article is licensed under a Creative Commons Attribution 4.0 International License, which permits use, sharing, adaptation, distribution and reproduction in any medium or format, as long as you give appropriate credit to the original author(s) and the source, provide a link to the Creative Commons licence, and indicate if changes were made. The images or other third party material in this article are included in the article's Creative Commons licence, unless indicated otherwise in a credit line to the material. If material is not included in the article's Creative Commons licence and your intended use is not permitted by statutory regulation or exceeds the permitted use, you will need to obtain permission 
directly from the copyright holder. To view a copy of this licence, visit http://creativecommons.org/licen ses/by/4.0/.

\section{References}

Akerlof, G. A. (1970). The market for "lemons": Quality uncertainty and the market mechanism. The Quarterly Journal of Economics, 84(3), 488-500.

Artfacts (2015-2019), Retrieved from www.artfacts.net.

ARTnews (2018), The ARTnews 200 top collectors. Report, Summer. New York: ARTnews.

Barrère, C., \& Santagata, W. (1999). Defining art. From Brancusi trial to the economics of artistic semiotic goods. International Journal of Arts Management, 1(2), 28-38.

Baudrillard, J. (1972). Pour une critique de l'économie politique du signe. Gallimard.

Baumol, W. J. (1986). Unnatural value: Or art investment as floating crap game. The American Economic Review, 76, 10-14.

Becker, G. S. (1965). A theory of the allocation of time. Economic Journal, 75, 493-517.

Belk, R. W. (1995). Collecting in a consumer society. Routledge.

Belk, R. W., Ger, G., \& Askegaard, S. (2003). The fire of desire: A multisited inquiry into consumer passion. Journal of Consumer Research, 30(December), 326-351.

Belk, R. W., Wallendorf, M., Sherry, J. F., \& Holbrook, M. B. (1991). Collecting in a consumer culture. In R. W. Belk (Ed.), Highways and Buyways: Naturalistic Research from the Consumer Behaviour Odyssey (pp. 178-215). Provo, UT: Association for Consumer Research. https://doi.org/10.4324/ 9780203167311.

Bergadaà, M. (1988). Le temps et le comportement de l'individu. Recherche Et Application En Marketing, 3(4), 57-72. https://doi.org/10.1177/076737018900400103.

Berry, M. J., \& Linoff, G. S. (2004). Data mining techniques (2nd ed.). Wiley.

Bloom, P. N., \& Reve, T. (1990). Transmitting signals to consumers for competitive advantage. Business Horizons, 33(4), 58-66.

Boorsma, M. (2006). A strategic logic for arts marketing: Integrating customer value and artistic objectives. International Journal of Cultural Policy, 12(1), 73-92. https://doi.org/10.1080/1028663060 0613333.

Botti, S. (2000). What role for marketing in the arts? an analysis of arts consumption and artistic value. International Journal of Arts Management, 2(3), 14-27.

Bourdieu, P. (1979). La distinction: Critique sociale du jugement. Editions de Minuit.

Bourgeon-Renault, D. (2000). Evaluating consumer behaviour in the field of arts and culture marketing. International Journal of Arts Management, 3(1(Fall)), 4-18.

Bradshaw, A. (2010). Before method: Axiomatic review of arts marketing. International Journal of Culture, Tourism and Hospitality Research, 4(10), 8-19. https://doi.org/10.1108/17506181011024724.

Candela, G., Castellani, M., \& Pattinoni, P. (2012). Tribal art market: Signs and signals. Journal of Cultural Economics, 36, 289-308.

Candela, G., Lorusso, S., \& Matteucci, C. (2009). Information, documentation and certification in western and ethnic art. Conservation Science in Cultural Heritage, 9, 47-78.

Candela, G., \& Scorcu, A. E. (2004). Economia delle arti. Zanichelli.

Caves, R. E. (2000). Creative industries: Contracts between art and commerce. Harvard University Press.

Cesarano, G. (1967), Il significato del collezionismo nella civiltà dei consumi, Spira Uno, 4 (JulyAugust), pp. 18-26.

Chen, Y. (2009). Possession and access: Consumer desires and value perceptions regarding contemporary art collection and exhibit visits. Journal of Consumer Research, 35(6), 925-940.

Chong, D. (2005). Stakeholder relationships in contemporary art. In I. Robertson (Ed.), Understanding international art markets and management (pp. 82-102). Routledge.

Codignola, F. (2015). The Globalization of the art market: A cross-cultural perspective where local features meet global circuits. In J. M. Alcántara-Pilar, S. Del Barrio-García, E. Crespo-Almedros, \& L. Porcu (Eds.), Analyzing the Cultural Diversity of Consumers in the Global Marketplace (pp. 82-100). Hershey, PA: Business Science Reference, IGI Global. https://doi.org/10.4018/978-15225-7116-2.ch071. 
Coffmann, R. B. (1991). Art investment and asymmetrical information. Journal of Cultural Economics, 15, 83-94.

Connelly, B. L., Certo, S. T., Ireland, R. D., \& Reutzel, C. R. (2011). Signaling theory: A review and assessment. Journal of Management, 37(1), 39-67.

Cova, B. (1996). Leçons de marketing postmoderne, L'Expansion Management Review, pp. 91-101.

Cyert, R. M., \& March, J. G. (1983). A behavioural theory of the firm. Prentice Hall.

Elkann, A. (2012), Pinault: "L'arte mi appassiona perché è una forma di dialogo universale”, http://www. lastampa.it/2012/12/02/cultura/imprenditore-e-collezionista-6X8Rb2xtYXMlYPh61DuuhN/pagina. html.

EMC Education Services. (2015). Data science and big data analytics: Discovering, analysing, visualizing and presenting data. Wiley.

Fillis, I. (2006). Art for art's sake or art for business sake: An exploration of artistic product orientation. The Marketing Review, 6, 29-40. https://doi.org/10.1362/146934706776861573.

Firat, A. F., \& Venkatesh, A. (1993). Postmodernity: The age of marketing. International Journal of Research in Marketing, 10, 227-249.

Frey, B. S. (2000). Arts \& economics. Springer. https://doi.org/10.1016/0167-8116(93)90009-n.

Ginsburgh, V. A., \& Throsby, D. (Eds.). (2006). Handbook of the economics of art and culture (Vol. 1). Elsevier.

Gnyp, M. (2015), Interview with François Pinault. Retrieved from http://www.martagnyp.com/inter views/francois-pinault.

Gourdon, A. M. (1982). Théatre, public, perceptions. Editions du CNRS.

Grappi, S., \& Montanari, F. (2009). Customer identification and retention: The determinants of intention to re-patronize in the film industry. International Journal of Arts Management, 12(1), 44-59.

Hand, C. (2018). Do the arts make you happy? A quantile regression approach. Journal of Cultural Economics, 42(2), 271-286.

Hetzel, P. (1996). Les enterprises face aux nouvelles formes de consummation, Revue Française de Gestion (September-October), pp. 70-82.

Hirschman, E. C. (1983). Aesthetics, ideologies and the limits of the marketing concept. Journal of Marketing, 47(Summer), 45-55. https://doi.org/10.2307/1251196.

Holbrook, M. B. (1980). Some preliminary notes on research in consumer aesthetics. In J. C. Olson (Ed.), Advances in Consumer Research (pp. 104-108). Ann Arbor, MI: Association for Consumer Research Editions.

Holbrook, M. B. (1986). Aims, Concepts, and methods for the representation of individual differences in aesthetics responses to design features. Journal of Consumer Research, 13(3), 337-347. https://doi. org/10.1086/209073.

Holbrook, M. B., \& Batra, R. (1987). Assessing the role of emotions as mediators of consumer responses to advertising. Journal of Consumer Research, 14, 404-420. https://doi.org/10.1086/209123.

Holbrook, M. B., \& Hirschman, E. C. (1982). The experiential aspects of consumption: consumer fantasies, feelings and fun. Journal of Consumer Research, 9, 132-140. https://doi.org/10.1086/208906.

Holt, D. B. (1995). How consumers consume: toward a typology of consumption practices. Journal of Consumer Research, 22(June), 1-25.

IBM (2012) SPSS Decision Trees 21, IBM Corporation.

Jackson, D. N. (1976). Is achievement a unitary construct? Journal of Research in Personality, 10, 1-21.

Jahn, G., Schramm, M., \& Spiller, A. (2005). The reliability of certification: Quality labels as a consumer policy tool. Journal of Consumer Policy, 28, 53-73.

Jolink, A., \& Niesten, E. (2020). Credibly reducing information asymmetry: Signaling on economic or environmental value by environmental alliances. Long Range Planning, in Press. https://doi.org/10. 1016/j.1rp.2020.101996.

Jyrama, A., \& Ayvari, A. (2010). Marketing contemporary visual art. Marketing Intelligence and Planning, 28(6), 723-735. https://doi.org/10.1108/02634501011078129.

Kass, G. V. (1980). An exploratory technique for investigating large quantities of categorical data. Applied Statistics, 29(2), 119-127.

Khalil, E. L. (2000). Symbolic products: Prestige, pride and identity goods. Theory and Decision, 49, 53-77.

Kotler, P., \& Armstrong, G. (2010). Principi di Marketing. Milano: Pearson Paravia Bruno Mondadori.

Kubacki, K., \& Croft, R. (2011). Markets, music and all that jazz. European Journal of Marketing, 45(5), 805-821. https://doi.org/10.1108/03090561111120046.

Lancaster, K. (1971). Consumer demand: New Approach. Columbia University Press. 
Lee, T. H., \& Crompton, J. (1992). Measuring novelty seeking in tourism. Annals of Tourism Research, 19, 732-751. https://doi.org/10.1016/0160-7383(92)90064-v.

Lehman, K., \& Wickham, M. (2014). Marketing orientation and activities in the arts-marketing context: Introducing a visual artists' marketing trajectory model. Journal of Marketing Management, 30(78), 664-696. https://doi.org/10.1080/0267257x.2013.838987.

Leja, M. (2000). Peirce, visuality, and art. Representations, 71, 97-122. https://doi.org/10.2307/2902910.

Levitt, T. (1980). Marketing success through differentiation-of anything, Harvard Business Review, January-February, pp. 83-91.

Martin, B. (2007). How visual artists enter the contemporary art market in France: A dynamic approach based on a network of tests. International Journal of Arts Management, 9(3), 16-33.

McAlister, L., \& Pessemier, E. (1982). Variety-seeking behaviour: an interdisciplinary review. Journal of Consumer Research, 9(12), 311-322. https://doi.org/10.1086/208926.

Mei, J., \& Moses, M. (2005). Beautiful asset: Art as investment. The Journal of Investment Consulting, $7(2), 1-7$.

Mellander, C., Florida, R., Rentfrow, P. J., \& Potter, J. (2018). The geography of music preferences. Journal of Cultural Economics, 42(4), 593-618.

Merlin, M. (2019). Gender (still) matters in Chinese Contemporary Art. Journal of Contemporary Chinese Art, 6(1), 5-15. https://doi.org/10.1386/jcca.6.1.5_2.

Molfino, F., \& Mottola Molfino, A. (1997). Il possesso della bellezza. Dialogo sui collezionisti d'arte. Allemandi.

Muensterberger, W. (1994). Collecting, an unruly passion: Psychological perspectives. Princeton University Press.

Palazzo Grassi (2015-2019), Retrieved from www.palazzograssi.it.

Polveroni, A., \& Agliottone, M. (2012). Il piacere dell'arte. Milano: Johan \& Levi Editore.

Rasmunsen, E. (2006). Games and information: An introduction to game theory. Wiley-Blackwell.

Reilly, M., \& Nochlin, L. (2007). Global feminisms: New directions in contemporary art. Brooklyn Museum and Merrell Publishers.

Sherry, J., \& Joy, A. (2003). Speaking of art as embodied imagination: A multi-sensory approach to understanding aesthetic experience. Journal of Consumer Research, 30(September), 259-282.

Shönfeld, S., \& Reinstaller, A. (2007). The effects of gallery and artist reputation on prices in the primary market for art: A note. Journal of Cultural Economics, 31, 143-153.

Shubik, M. (2003). Dealers in art. In R. Towse (Ed.), A handbook of cultural economics (pp. 194-200). Edward Elgar.

Slack, F., Rowley, J., \& Coles, S. (2008). Consumer in multi-channel contexts: The case of a theatre festival. Internet Research, 18(1), 46-59.

Solomon, M. R. (1983). The role of products and social stimuli A Symbolic interactionism perspective. Journal of Consumer Research, 10(3), 319-329. https://doi.org/10.1086/208971.

Tirole, J. (1998). The theory of industrial organization. The MIT Press.

Veblen, T. (1899). The theory of the leisure class: An economic study of institutions. Macmillan.

Velthuis, O. (2005). Talking prices: Symbolic meanings of prices on the market for contemporary art. Princeton University Press. https://doi.org/10.1515/9781400849406.

Velthuis, O. (2012). The contemporary art market between stasis and flux. In M. Lind \& O. Velthuis (Eds.), Contemporary Art and its Commercial Markets. A Report on Current Conditions and Future Scenarios. Berlin: Sternberg Press.

Velthuis, O., \& Baia Curioni, S. (2015). Cosmopolitan canvases, the globalization of markets for contemporary art. Oxford University Press. https://doi.org/10.1093/acprof:oso/9780198717744.001.0001.

Venkatesh, A., \& Meamber, L. A. (2006). Arts and aesthetics: Marketing and cultural production. Marketing Theory, 6(1), 11-39. https://doi.org/10.1177/1470593106061261.

Wheatley, D., \& Bickerton, C. (2017). Subjective well-being and engagement in arts, culture and sport. Journal of Cultural Economics, 41(1), 23-45.

Zorloni, A., \& Willette, R. (2014). Managing art wealth: creating a single family office which preserves and protects the family art collection. Journal of Wealth Management, 16(4), 9-17. https://doi.org/ 10.3905/jwm.2014.16.4.009.

Zuckerman, M. (2014). Sensation Seeking: Beyond the Optimal Level of Arousal. London: Psychology Press. https://doi.org/10.4324/9781315755496. 